\title{
Performance of elite grain sorghum varieties in the West Nile Agro-ecological Zones
}

\author{
E. Awori, M. Kiryowa, A. Basirika, F. Dradiku, R. Kahunza, A. Oriba, C. Edonia, R. Olupot ${ }^{1}$ \\ and J. Mukalazi
}

Abi Zonal Agricultural Research and Development Institute (AbiZARDI), P. O. Box 219 Arua, Uganda

${ }^{1}$ National Semi-arid Resources Research Institute (NaSARRI), Serere, Uganda

Author for correspondence: eresmiracle@yahoo.com

\begin{abstract}
Grain Sorghum (Sorghum bicolor (L.) Moench) is the fifth most important cereal in the world and third most important cereal crop in Uganda. In the West Nile region of Uganda, it is the most important cereal crop. Ten pre-released sorghum varieties, acquired from the National SemiArid Resources Research Institute, were evaluated on-station at Abi Zonal Agricultural Research and Development Institute during the second rainy seasons of 2011 and 2013 to identify suitable lines for the region. The four most promising varieties in 2011 were further evaluated in 2012 and 2013 under five different spacings namely; $60 \mathrm{~cm} \times 20 \mathrm{~cm}, 45 \mathrm{~cm} \times 20 \mathrm{~cm}, 35 \mathrm{~cm} \times 20 \mathrm{~cm}, 25$ $\mathrm{cm} \times 20 \mathrm{~cm}$ and $15 \mathrm{~cm} \times 20 \mathrm{~cm}$. Sorghum lines evaluated significantly differed in grain yields $(\mathrm{P}<\mathbf{0 . 0 5})$. All parameters were significantly $(\mathrm{P}<0.05)$ affected by spacing, except days to $50 \%$ flowering and number of tillers. The best yielding varieties were GAO9/25(1,975 kg ha-1) and GA06/33 (1,637 kg ha-1) and the least yielding was NASECO $\left(38.7 \mathrm{~kg} \mathrm{ha}^{-1}\right)$ and Epuripuri $(31.3 \mathrm{~kg}$ $\left.\mathrm{ha}^{-1}\right)$. The $35 \mathrm{~cm} \times 20 \mathrm{~cm}$ spacing resulted in the highest yield $\left(2,740.7 \mathrm{~kg} \mathrm{ha}^{-1}\right)$ and is recommended for sorghum growing in West Nile region.
\end{abstract}

Key words: Flowering, Sorghum bicolor, spacing

\section{Introduction}

Sorghum (Sorghum bicolor (L.) (Moench) is a major part of the dietary and the third most important staple cereal food crop in Uganda, occupying 265,000 hectares of arable land (Ebiyau et al., 2005). The crop is mainly grown in the south-western highlands, eastern and northern lowland areas of Uganda (Ebiyau et al., 2005). It is regarded as a food security crop because of its adaptability to the semi-arid conditions (Ouma and Akuja, 2013). In West Nile, the crop is grown by almost every household (Abi ZARDI, 2014).

Although the area planted to sorghum remains stable, production has decreased 
from 467,000 metric tonnes in 1975 to 320,000 tonnes in 2013 (USDA, 2013). This yield decline, especially in West Nile is attributed to both biotic and a biotic factors such as low seed quality, poor soil fertility, poor agronomic management practices and long maturity periods of the existing varieties.

Fertiliser use on sorghum is rare and many farmers do not even use the available manure (Abi ZARDI, 2014). In addition, farmers in West Nile broadcast sorghum while planting; as a result, the fields are usually overcrowded due to high plant population and difficulty management. This also gives opportunity to invasive weeds like Striga spp to attack the crop, especially in the less fertile soils (Odama et al., 2013). Furthermore, high competition for the little nutrient available results in poor establishment of sorghum plants thus low yields.

Most of the varieties grown by farmers in this region take up to 9 months to mature with relatively low yield $(1,100$ $\mathrm{kg} \mathrm{ha}^{-1}$ ), compared to the improved varieties which take only three months to mature and can yield up to $3,500 \mathrm{~kg} \mathrm{ha}^{-1}$ (Awori and Odama, 2014 un published data).

The Low yields of local varieties, coupled with unpredictable weather changes within the West Nile region, pose a threat to farmers who depend on sorghum for food security. Introduction of early maturing and high yielding varieties would help farmers cope with seasonal changes. The objective of this study was to identify the best performing varieties to be availed to farmers in the region.

\section{Pre-release evaluation of elite sorghum varieties}

This part of the study was conducted at Abi Zonal Agricultural Research and Development Institute (Abi ZARDI) during 2011B and 2012B (July - October) rainy cropping seasons. Abi ZARDI is located in Arua district, North western Uganda. It lies within $3^{\circ} 4.58^{\prime} \mathrm{N}$ and $30^{\circ} 56.74^{\prime} \mathrm{E}$ and $1206 \mathrm{~m}$ above sea level.

Ten advanced sorghum breeding lines, together with two released varieties; Sekedo and Epuripuri (improved checks) were used as treatments (Table 1). The study was established on-station in a randomised complete block design (RCBD), on plots of $3.5 \mathrm{mx} 1.5 \mathrm{~m}$, with three replications. All the varieties were planted at a spacing of $60 \mathrm{~cm}$ between rows and after 3 weeks, they were thinned to approximately $20 \mathrm{~cm}$ within rows.

Table 1. Elite sorghum varieties used in a suitability study at Abi ZARDI in Uganda

\begin{tabular}{lll}
\hline Entry & Identity & Colour \\
\hline E1 & GA06/80 & Red \\
E2 & GA09/25 & Red \\
E3 & NASECO & Cream \\
E4 & EPURIPURI & White \\
E5 & GA010/008 & White \\
E6 & 4EA78/FS/1/1 & Brown \\
E7 & GA08/07 & White \\
E8 & SEKEDO & Brown \\
E9 & GA010/010 & White \\
E10 & GA010/009 & White \\
E11 & LDRM9/2/2 & Brown \\
E12 & GA06/33 & Cream \\
\hline
\end{tabular}


Data were collected on randomly selected plants in the middle of two rows of each plot, a modification of Hussain $e t$ al. (2011). The parameters considered included plant height at harvest, seed set at harvest, lodging, seedling vigour, days to $50 \%$ flowering, plant stand at harvest, number of panicles per plot, average dry panicle weight per plant, 1000-grain weight and yield. Vigour was measured using a scale of 1 (most vigorous) to 5 (least vigorous); while plant height was measured at physiological maturity from ground surface to the point where the flag leaf extends from the stalk (Abel and Pollack, 1991). Fifty percent flowering was recorded when $50 \%$ of the plants had completely headed. Seed set was recorded as the percent of the panicle with wellformed grains. Dry panicle weight was computed as an average of the weight of five dry panicle before threshing. Grain yield per hectare was also computed from grain yield per plot.

Data collected were analysed using the general linear module procedure (PROC GLM) of SAS (2003). Significant differences among means were determined using Duncan's method of mean separation.

\section{Variety selection by farmers}

At the end of 2012B cropping season, variety selection was conducted by 14 farmers. This was to help identify varieties with potential to perform better in the region as well as those likely to be preferred by the communities.

Seven male and seven female farmers of 25 to 45 years were invited at Abi ZARDI when elite pre-released and with two released sorghum varieties reached physiological maturity. They were then asked to carefully observe all the varieties in the three replicates and choose their best six varieties, specifying the reasons for the choice. Farmers selected the best performing varieties based on yield, seed size, panicle size, prevalence of pests and diseases, degree of lodging, time of maturity, degree of head filling, seed colour, drought tolerance, and softness of the seeds among others. They used a scale of 1 (best preferred) to 6 (least preferred). The ranks given for each variety were summed up for all the participants, considering the first six varieties selected. Out of the six selected varieties, four of them were used in the following study.

\section{Plant evaluation}

This part of the study was also conducted at Abi ZARDI in 2012B and 2013B rainy season. Four promising varieties from study I were planted under five different inter-row spacings namely, 60 (A), 45 (B), 35 (C), 25 (D) and $15 \mathrm{~cm}$ (E), laid out in a randomised complete block design. Intrarow spacing was maintained at $20 \mathrm{~cm}$ for each inter-row spacing. The same plot size, number of replicates and agronomic management practices were as in the first study.

The parameters considered in data collection were as in study I, in addition to average plant stand after thinning, number of tillers and seed set. Measurement of the parameters and data analysis was done as in the first study.

\section{Results}

\section{Growth and yield}

All parameters were significantly $(\mathrm{P}<0.05)$ different among varieties, except number of panicles per hectare, panicle diameter and 1000 grain weight (Table 2). The highest seedling vigour (2.7) was found in three varieties namely Sekedo (the improved check), GA010/010 and GA010/ 
Table 2. Agronomic and yield performance of the different pre-released sorghum varieties

\begin{tabular}{|c|c|c|c|c|c|c|c|c|c|c|c|c|c|}
\hline Parameter & E1 & E2 & E3 & E4 & E5 & E6 & E7 & E8 & E9 & E10 & E11 & E12 & SE \\
\hline Germination (\%) & 90 & 96 & 90 & 91.7 & 97 & 95.3 & 89.3 & 91 & 94.3 & 83.3 & 94.5 & 90 & 2.91 \\
\hline Seedling vigour & 1.5 & 1.7 & 2.3 & 2 & 2.3 & 1.7 & 1.3 & 2.7 & $2.7^{\mathrm{a}}$ & 2.7 & 1.5 & 1.7 & 0.36 \\
\hline Days to $50 \%$ flowering & 23 & 23 & 28.7 & 25.7 & 19 & 22 & 29 & 18 & 21.5 & 18 & 19.8 & 27 & 1.81 \\
\hline Plant height at harvest & 140 & 144 & 124 & 127 & 101 & 127 & 174 & 104 & 104 & 121 & 147 & 145 & 11 \\
\hline Plant stand at harvest & 53,250 & 61,333 & 51,000 & 68,833 & 63,333 & 57,333 & 61,833 & 58,167 & 56,000 & 47,500 & 63,500 & 55,000 & 59,244 \\
\hline Lodging \% & 30 & 17.7 & 1.3 & 1 & 17.3 & 36 & 1 & $7.3 b$ & 18.7 & 7 & 31.3 & 12.7 & 7.95 \\
\hline Number of panicle $\mathrm{ha}^{-1}$ & 60,290 & 80,667 & 52,833 & 62,333 & 71,833 & 83,667 & 74,000 & 78,667 & 69,833 & 74,000 & 73,375 & 76,833 & 10,439 \\
\hline Panicle length & 15.8 & 20.8 & 22.1 & 19.4 & 20.8 & 16.4 & 20.3 & 21.5 & 20.5 & 18.2 & 19.8 & 18.1 & 1.55 \\
\hline Panicle diameter & 9.1 & 10.1 & 10.3 & 9.5 & 9 & 7.7 & 9.9 & 8.4 & 7.5 & 8.4 & 9.1 & 9.9 & 1.06 \\
\hline Panicle weight & 29.7 & 27.9 & 12.7 & 11.2 & 13.3 & 17.4 & 16.4 & 29.7 & 7.1 & 10.9 & 26.3 & $30.2^{\mathrm{a}}$ & 4.98 \\
\hline 1000 grain weight & 15 & 16.7 & 13.3 & 10 & 10 & 20 & 16.7 & 20 & 13.3 & 13.3 & 17.5 & 20 & 3.02 \\
\hline Grain yield $\left(\mathrm{ha}^{-1}\right)$ & 1,275 & 1,975 & 38.7 & 31.3 & 90.7 & $1,175.8$ & 39.5 & 916.8 & 81 & 42.5 & $1,293.8$ & $1,636.7$ & 175.68 \\
\hline
\end{tabular}

E1(GA06/80),E2(GA09/25), E3(NASECO),E4(EPURIPURI), E5(GA010/008), E6(SEKEDO), E7(GA08/07), E8(SEKEDO), E9(GA010/010), E10(GA010/009), E11(LDRM9/2/2),E12(GA06/33) 
009, and the lowest (1.3) in GA08/07. Days to $50 \%$ flowering were highest in GA08/07 (29) and lowest in Sekedo and GA010/009 (18). The highest plant height at harvest was in GA08/07 (174.1 cm), while the lowest was observed in GA010/ $008(101 \mathrm{~cm})$.

The highest percentage germination was observed in GA010/008 (97\%) and the lowest in GA010/009 (83.3\%). Plant stand at harvest was highest in Epuripuri $(68,833)$; while lowest was in GA010/009 $(47,500)$. The highest panicle length was observed in NASECO $(22.1 \mathrm{~cm})$ and lowest in GA06/80 $(15.8 \mathrm{~cm})$. Panicle weight was highest in GA06/33 (30.2 g); while the lowest was in GA010/010 (7.1 g). Grain yield was highest in GA09/25 $\left(1,975 \mathrm{~kg} \mathrm{ha}^{-1}\right)$, followed by GA06/33 $\left(1,636.7 \mathrm{~kg} \mathrm{ha}^{-1}\right)$ and least in Epuripuri (31.3 kg ha-1).

\section{Farmer variety selection}

The most important criteria for which the best six varieties were selecting were good yield, low levels of disease incidence, low levels of bird damage followed by early maturity considered for at least five varieties (Table 3). Varieties 4EA78/FS/1/ 1(E6), LDRM9/2/2 (E11) and GA06/33 (E12) had the highest score (67\%) for all the attributes given by farmers and some of the qualifying factors they had unlike others were big seed sizes, desirable colour and high percentage of panicle fill (Table 3). However, in general terms, variety GA06/33 (E12) was selected as best performing, followed by GA09/25 (E2), GA06/80 (E1), 4EA78/FS/1/1(E6), LDRM9/2/2 (E11) and Sekedo (E8), in that order (Table 4).

\section{Plant spacing}

All parameters were significantly $(\mathrm{P}<$ 0.05 ) influenced by spacing, except days

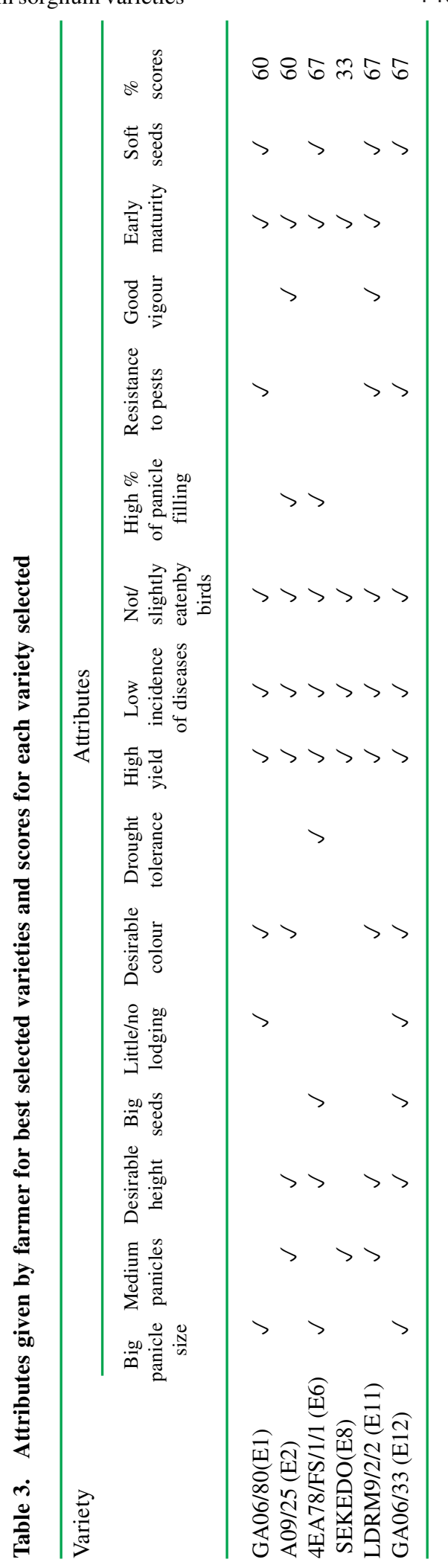


Table 4. Farmer scores and ranks for best six selected elite sorghum varieties

\begin{tabular}{|c|c|c|c|c|c|c|c|c|}
\hline \multirow[t]{2}{*}{ Variety } & \multicolumn{6}{|c|}{ **Ranks (Number of farmers ) } & \multirow{2}{*}{$\begin{array}{l}\text { Total } \\
\text { scores }\end{array}$} & \multirow{2}{*}{$\begin{array}{c}\text { Mean } \\
\text { rank }\end{array}$} \\
\hline & 1 & 2 & 3 & 4 & 5 & 6 & & \\
\hline GA06/80 (E1) & 1 & 4 & 2 & 3 & 2 & 2 & 49 & 3.5 \\
\hline $\mathrm{A} 09 / 25(\mathrm{E} 2)$ & 3 & 5 & 1 & 2 & 0 & 3 & 42 & 3 \\
\hline 4EA78/FS/1/1(E6) & 1 & 2 & 4 & 2 & 2 & 3 & 53 & 3.7 \\
\hline SEKEDO (E8) & 0 & 0 & 0 & 4 & 7 & 3 & 69 & 4.9 \\
\hline LDRM9/2/2(E11) & 0 & 1 & 4 & 3 & 3 & 3 & 59 & 4.2 \\
\hline GA06/33(E12) & 9 & 2 & 3 & 0 & 0 & 0 & 22 & 1.6 \\
\hline
\end{tabular}

** Ranks imply number of farmers that chose the varieties as their $1^{\text {st }}, 2^{\text {nd }}, 3^{\text {rd }}, 4^{\text {th }}, 5^{\text {th }}$ or $6^{\text {th }}$ choice

to $50 \%$ flowering, number of tillers and 1000 grain weight (Table 5). The best seedling vigour (1.5) was recorded under spacing $15 \mathrm{~cm} \times 20 \mathrm{~cm}$; while the lowest (3) was recorded under spacing $60 \mathrm{~cm} \times$ $20 \mathrm{~cm}$.

The highest number of plants at thinning $(236,667)$ and at harvest $(143,810)$ was recorded under spacing $15 \mathrm{~cm} \times 20 \mathrm{~cm}$; while the lowest stand after thinning $(75,079)$ and harvest $(72,381)$ were recorded under $60 \mathrm{~cm} \times 20 \mathrm{~cm}$. Lodging was generally, less than $1 \%$ under all spacings. The highest lodging $(0.0083 \%)$ was recorded under spacing $45 \mathrm{~cm} \times 20$ $\mathrm{cm}$. Lodging, however, did not occur under spacings $60 \mathrm{~cm} \times 20 \mathrm{~cm}, 35 \mathrm{~cm} \times 20 \mathrm{~cm}$ and $15 \mathrm{~cm} \times 20 \mathrm{~cm}$.

Plant height at harvest generally increased with reduced inter-row spacing. The highest $(166.81 \mathrm{~cm})$ plant height was observed under spacing $15 \mathrm{~cm} \times 20 \mathrm{~cm}$ and lowest $(149.75 \mathrm{~cm})$ under spacing 60 $\mathrm{cm} \times 20 \mathrm{~cm}$. The number of panicles per ha was highest $(153,810)$ under spacing $25 \mathrm{~cm} \times 20 \mathrm{~cm}$ and lowest $(11,127)$ under spacing $45 \mathrm{~cm} \times 20 \mathrm{~cm}$. The highest seed set $(86.75 \%)$ was observed under $60 \mathrm{~cm}$ $\times 20 \mathrm{~cm}$ spacing and the lowest $(63.17 \%)$ was observed under $15 \mathrm{~cm} \times 20 \mathrm{~cm}$.
Generally, grain yield increased with decreasing spacing up to a $2,740.7 \mathrm{~kg}$ maximum beyond which it began to decline. The highest grain yield $(2,740.7$ $\mathrm{kg}$ ) was observed under spacing $35 \mathrm{~cm} \times$ $20 \mathrm{~cm}$, and the lowest $(2,314.8 \mathrm{~kg})$ at the spacing $45 \mathrm{~cm} \times 20 \mathrm{~cm}$.

Days to $50 \%$ flowering were highest (76.8) under $45 \mathrm{~cm} \times 20 \mathrm{~cm}$ spacing and lowest (75.5) under spacing $60 \mathrm{~cm} \times 20 \mathrm{~cm}$. The number of tillers was highest (3) under spacing $60 \mathrm{~cm} \times 20 \mathrm{~cm}$ and $15 \mathrm{~cm} \times 20$ $\mathrm{cm}$, and lowest (2.4) under spacing $25 \mathrm{~cm}$ $\times 20 \mathrm{~cm}$. A thousand grain weight was highest ( $20 \mathrm{~g}$ ) under spacing $45 \mathrm{~cm} \times 20$ $\mathrm{cm}$, and lowest $(17.5 \mathrm{~g})$ under spacing 25 $\mathrm{cm} \times 20 \mathrm{~cm}$.

\section{Discussion}

\section{Growth and yield}

Plant height was significantly $(\mathrm{P}<0.05)$ different among all the varieties (Table 2). This is naturally a genetic trait which is expected for different plant varieties. It should however, be noted that in very tall varieties, the plant spends more energy in growth than head filling, which may result in low grain yield. This could have been the case with GA08/07(E7) in the present 
study. It had the tallest plants, but was also among the least yielding, despite its high number of panicles ha ${ }^{-1}$, relatively heavy panicles and 1000 grain weight (Table 2). The results showed a significant $(\mathrm{P}<0.05)$ difference in the days to $50 \%$ flowering among the varieties and majority of the varieties that flowered within 24 days gave higher grain yields. This may imply that such varieties had better adaptability to conditions within the West Nile region. Hussain et al. (2011) also suggests that flowering time is an indication of the potential of particular varieties to adapt to extreme conditions like drought and water stress. Early flowering varieties have the potential to adapt to such extreme conditions above and even to natural selection, better than the late flowering varieties. These results were similar to those obtained by Muturi et al. (2012) and Ouma and Akuja (2013), and also confirm the theories of Haussmann et al. (2006), that early anthesis in sorghum hybrid was the most important specific adaptation to extreme drought.

Germination was generally above acceptable minimum $(85 \%)$ in all varieties, except in GA010/009 (E10), which was $83.3 \%$ (Table 2). However, plant stand was significantly different among the varieties; implying varieties with more plants have the potential to yield better, though this was not the case. Varieties like Epuripuri (E4), GA010/008 (E5), GA08/ 07(E7) and GA010/010 (E9) that had very high densities per plot at harvest, had relatively very low grain yields. This could have been due to other factors like conspicuousness to birds given their white colour and susceptibility to diseases like smuts as observed in the field.

Results showed significant $(\mathrm{P}<0.05)$ difference in panicle weight and grain yield among varieties (Table 2 ), which results 
are similar to those obtained by Osmanzai (1994) and Hussain et al. (2011).This implies that under similar environmental conditions particular varieties are able to adapt and therefore perform better in this case GA06/80 (E1), GAO9/25 (E2), 4EA78/FS/1/1 (E6), LDRM9/2/2 (E11) and GA06/33 (E12) than the other prereleased varieties.

Low grain yield in sorghum lines, coupled with low panicle weight could have been attributed to fewer grains attached to the panicle, lighter grains or small panicle sizes, thus carrying fewer seeds attached. In the results (Table 2), varieties that performed best in terms of grain yield, GA06/80 (E1), GAO9/25 (E2), 4EA78/FS/1/1 (E6), Sekedo, LDRM9/2/ 2 (E11) and GA06/33 (E12) had relatively heavy panicles and heavier grains. This implies that such varieties possess superior genetic potential, high water use efficiency and better adaptability to the region.

Although the 1000 grain weight was not significantly $(\mathrm{P}<0.05)$ different among the varieties (Table 2) in this study, the highest weights were observed on those varieties which gave the best yields. This implies that grain weight is a major component of total grain yield for a variety and is also an indication of the level of adaptability among varieties.

\section{Farmer varietal selection}

Farmers used such attributes as high yields, resistance to diseases, resistance to bird damage and early maturity as the most important criteria for selection of the best sorghum varieties (Table 3 ). This finding conforms to those of Obaa et al. (2005), while selecting the best performing hybrid maize varieties through farmer participatory evaluation in Nebbi district. The fact that GA09/25 (E2) and GA06/ 80 (E10) were selected as the second and third best performers despite inferior scores (Table 4) for the best attributes, implies farmers diverse perceptions and complex combinations of criteria they use in selecting the sorghum varieties they grow. Nevertheless, their choices are important because they have implications on uptake of the technologies.

\section{Plant spacing}

Plant height at harvest significantly increased with reduced spacing (Table 5). This could be attributed to morphological changes in densely populated plants (taller plants with thinner stems), resulting from higher seed rates under the narrow row spacings. These results were similar to those obtained by Snider et al. (2012) who tested the performance of grain sorghum under three different spacings $(19,38$ and $78 \mathrm{~cm})$ and discovered that plant height increased with increased seedling rate. Adam et al. (2013).also confirmed that plant height increased with reduced spacing.

Yield per hectare was significantly $(\mathrm{P}<0.05)$ affected by inter-row spacing, and increased with reduced spacing to a maximum, after which it started reducing. These results are similar to those reported by Snider et al. (2012) and Adam et al.(2013) who observed significantly $(\mathrm{P}<0.05)$ higher yields in narrow row spacings than in the wider inter row spacing. This could be attributed to an increase in the population density to an optimum, beyond which there was poor light penetration in the canopy, reduced photosynthesis due to shading of lower leaves thus resulting in yield loss. 


\section{Conclusion}

GA06/80 (E1), GAO9/25 (E2), 4EA78/ FS/1/1 (E6), Sekedo, LDRM9/2/2 (E11) and GA06/33 (E12) are better suited for the West Nile region. Inter-row spacing of $35 \mathrm{~cm} \times 20 \mathrm{~cm}$ is the best for obtaining optimum grain sorghum yield, hence, spacing serves as a convenient management practices in crop research.

\section{Acknowledgement}

The authors are grateful to the scientists and general administration of Abi ZARDI for their continued support and cooperation, and to the National Agricultural Research Organization, Uganda for funding this research.

\section{References}

Abel, B. C. and Pollack, L.M. 1991. Rank comparison of un-adapted maize populations by testers and per se evaluation. Crop Science 31: 650-656.

Adam. K.L, Ali. S.A.M, Bahar. A. H, Hassan. T. A., 2013. Effect of Plant Spacing and Variety on Performance of Rain-Fed Pearl Millet (Pennisetum Glaucum 1) Grown on Two Soil Types at Zalingei Area, Sudan. ARPN Journal of Science and Technology 3(5): 512-517.

Ebiyau, J., Arach, T and Serunjogi, L.K. 2005. Commercialisation of Sorghum In Uganda. African Crop Science Conference Proceedings 7:695-696.

Haussmann, B., Schipprack, I.G. and Geiger, H.H. 2006. Hybrid performance of sorghum and its relationship to morphological and physiological traits under variable drought stress in Kenya. Plant Breeding 117(3):223-229.
Hussain, N., Baloch, M.S., Yousaf, M., Naeem, M., Khakwani, A.A. and Begum, I. 2011. Performance of sorghum varieties in Potohar region. Gomal University. Journal of Research 27(2):26-30.

Muturi, P.W., Rubaihayo, P., Kyamanywa, S., Mgonja, M. and Sharma, H.C. 2012. Performance of selected grain sorghum genotypes for improved food security and livelihoods. Research Application Summary in the third RUFORUM Biennial : 257-260.

Obaa, B., Chanpacho, M. and Agea, J.G. 2005. Participatory farmer evaluation of maize varieties: A case study from Nebbi District, Uganda. African Crop Science Conference Proceedings 7: 1389-1393.

Odama, E., Dradiku, F., Avako, M. and Kahuza, R. 2013. West Nile Soil fertility improvement end of Project Report. Abi ZARDI, National Agricultural Research Organization, Arua, Uganda.

Osmanzai, M. 1994. Relative performance of sorghum hybrids and open pollinated cultivars under two soil moisture regimes. Intl. Sorghum and Millet Newslett. 35: 131.

Ouma, J.P. and Akuja, T.E. 2013. Agronomic and morphological performance of sorghum (Sorghum bicolor L.) for the dry highlands of Kenya. www.m.elewa.org

Schatz, B.G., Schneiter, A.A. and Gardner, J.E. 1987. Effect of plant density on grain sorghum production in North Dakota. pp. 16-17.

Snider, J.L., Randy, L.R. and Eric, B. S. 2012. The effect of row spacing and seeding rate on biomass production and plant stand characteristics of nonirrigated photoperiod-sensitive sorghum (Sorghum bicolor (L.) 
Moench). Industrial Crops and Statistics Service. U.S. and All States Products 37: 527- 535.

United States Department of Agriculture (USDA), 2012. National Agricultural

Data-Crops. National Agricultural Statistics Service. Accessed on 28 January, 2012. 